\title{
Investigation on Haze Attenuation Impact on Proposed SCM-SAC-OCDMA Based on FSO System by Using MD Code
}

\author{
H. S. Mohammed ${ }^{1}$, A. Ahmad ${ }^{2}$, Samuel Dowse ${ }^{3}$ \\ ${ }^{1}$ School of Computing, College of Arts and Sciences, Universiti Utara Malaysia, Malaysia, \\ hussein_saad@ahsgs.uum.edu.my \\ ${ }^{2}$ Internetworks Research Laboratory, School of Computing, College of Arts and Sciences, Universiti Utara \\ Malaysia, Malaysia, amran@uum.edu.my \\ ${ }^{3}$ Engineering, Ministry of Australian Defense, Australia, sambodowse88@hotmail.com
}

\begin{abstract}
The performance of the subcarrier multiplexing with spectral amplitude code optical code division multiplying access (SCM-SAC-OCDMA) system based on Free Space Optic (FSO) by using MD code has been investigated, which reduces the MAI and increase the number of users. The proposed system can overcome the weather condition problems, i.e., haze. The proposed system shows superior performance in terms of bit error rate (BER). For example, in the heavy haze condition of Malaysia, when the FSO link is $23.3 \mathrm{~km}$ and the value of BER becomes $2.7 \times 10^{-9}$. Thus, the proposed system is a potential candidate for future broadband access solutions in communication networks. The proposed SAC-OCDMA-FSO using the SCM system shows better performance compared with the conventional SAC-OCDMAFSO system and the number of users improves by $31.8 \%$.
\end{abstract}

Key words: SCM-SAC-OCDMA, FSO, RF, MAI, MD code.

\section{INTRODUCTION}

Radio and fiber networks are well suited to build WLAN-based WiFi networks of extended OCDMA systems without imposing stringent limits on the size of the optical backhaul, as opposed to radio over fiber $(\mathrm{RoF})$ networks that limit the length of deployed fibers to a couple of kilometers [1]. The new RoF techniques are proposed which demonstrate the benefits of Subcarrier Multiplexing (SCM) over OCDMA networks [2] that provide a way for several radio signals to access the OCDMA networks. SCM demonstrates potential to be a convenient and efficient technique for transmission of analog or digital information. However, SCM offers a promising system to solve the needs of telecommunication networks [3]. The proposed system provides the necessary bandwidth for transmission of the broadband data to end-users In contrast, Spectral Amplitude Coding-Optical

Code Division Multiple Access (SAC-OCDMA) system can support a higher number of simultaneous users compared to other OCDMA techniques [3]. However, the SAC-OCDMA system can suffer from interference such as shot noise, thermal noise, dark current and multiple-access interference (MAI) from other users. Among these noises, MAI is considered as a dominant source of system performance degradation [4]. Therefore, it is logical to search for a new technique to employ in SAC-OCDMA system that can meet the expected performance requirements in a simple and cost-effective way. In addition, SAC-OCDMA system that can use FSO and transfer high data rate, which limited users [5]. On the other hand, FSO is vulnerable to fluctuation atmosphere phenomena. Weather conditions such as haze are capable to attenuate the beam light and in certain circumstances, able to hinder the light passage through the combination of absorption, scattering and reflection [6]. The work covered in this research apply SCM-SAC-OCDMA system by using MD code based on FSO in order to overcome haze attenuations, increasing the number of users and reduce the effect of the MAI. MD code is designed based on a combination of diagonal matrixes [7]. The MD code has several advantages, such as: zero cross-correlation code which reduces the MAI, simple design, supports many users at a high data rate compared to other codes, and no overlapping of spectral for different users. This paper is organized as follows: in section 2 , is discuses haze attenuation is presented. In Section 2, Haze attenuation. Section 3, it reviews the design parameters of a subcarrier multiplexing SAC-OCDMA-FSO system and discuses the mathematical model of the proposed SCM -SAC-OCDMA system based on FSO. Section 4, it presents the comparative between SCM-SAC-OCDMA-FSO system and SAC-OCDMA-FSO system by using MD code. Section 5, the system result of SCM-SAC-OCDMA-FSO System and SAC-OCDMA -FSO System by using MD Code. Finally, the paper concludes with a summary of findings.

\section{HAZE ATTENUATION}

W Attenuation by haze in FSO systems is determined found by obtaining the scattering coefficient. Estimation of the scattering coefficient depends on visibility conditions. The concentration and size of the particles under low visibility are higher than that under average visibility. At a given wavelength $\lambda$ (in nanometers), the attenuation coefficient is 
approximated by [8].

$$
\begin{aligned}
& \alpha_{\text {spec }}(\lambda)=(3.912 / \mathrm{V})(\lambda / 550)^{-\mathrm{q}} \\
& \alpha_{\text {spec }}=10 \log e^{\alpha_{\text {spec }}(\lambda)}(\mathrm{dB} / \mathrm{Km})
\end{aligned}
$$

where $\alpha$ spec is attenuation by haze $(\mathrm{dB} / \mathrm{km}), \lambda$ is wavelength $(\mathrm{nm}), \mathrm{v}$ is visibility $(\mathrm{km})$, and $\mathrm{q}$ is a coefficient that is dependent on the size distribution of scattering particles, is exploited by the Kruse model $[9,10]$, and is implemented in our simulation analysis. The Kruse model defines $\mathrm{q}$ as follows:

$$
q=\left\{\begin{array}{l}
1.6, \quad \quad v>50 \mathrm{Km} \\
1.3, \quad 6 \mathrm{Km}<v<50 \mathrm{Km} \\
0.16 v+0.43, \quad \quad \quad \quad \mathrm{Km}<v<6 \mathrm{Km} \\
v-0.5, \quad v<0.5 \mathrm{Km} \\
0, \quad \quad v 6 m
\end{array}\right.
$$

\section{DESIGN PARAMETERS OF SCM-SAC-OCDMA-FSO SYSTEM}

The proposed SCM-SAC-OCDMA system network design based on MD code is shown in Fig.1. At the transmitter side, an external optical modulator is used to merge data with an independent unipolar digital signal that is optically modulated into the code sequence [1]. A Mach-Zehnder modulator (MZ) is used to combine the RF signal with the code sequences and transmit to the FSO link [11]. Meanwhile, at the receiver side, an optical splitter is used to separate the various modulated code sequences. The MD code sequences are filtered by using fiber Bragg grating (FBG) filters and transferring them to the Photodetector (PD) at the receiver [1]. Consequently, SCM signals that are combined with each $\mathrm{MD}$ code sequence are split by an electrical splitter and a Band Pass Filter (BPF) to filter and reject unwanted signals. Figure 1 also illustrates the scheme designed for the proposed SCM-SAC-OCDMA-FSO system and shows the implementations of the proposed system.

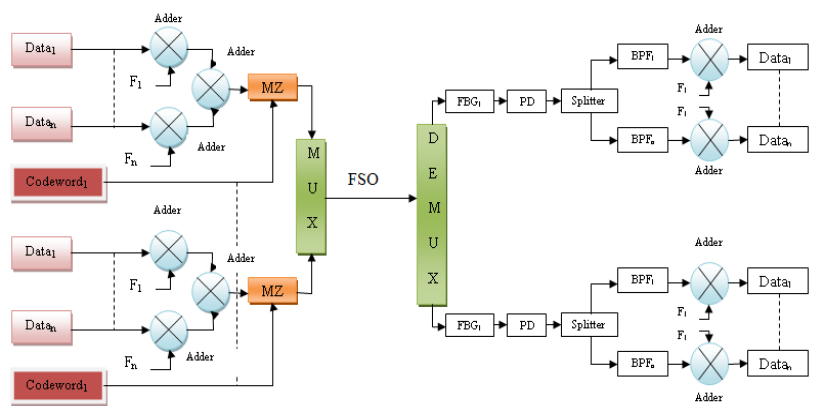

Figure 1: System Design of the Proposed SCM-SAC-OCDMAFSO System.

The performance of the SCM-SAC-OCDMA system based on
FSO is greatly affected by weather conditions. Poor weather conditions cause low SNR value and an increased bit error rate (BER), which is calculated by Gaussian approximation [12]. It considered the effects of thermal noise $\left(I_{t h}^{2}\right)$, and shot noise ${ }^{\left(I_{s h}^{2}\right)}$, Intermodulation distortion $I_{\text {uo }}^{(2)}$ in the p Photodetectors, as well as the effect of haze attenuation $\left[\alpha_{\text {spec }}(\lambda)\right]$ on the signal power received $\left(\mathrm{P}_{\mathrm{sr}}\right)$. The $\mathrm{SNR}$ of an electrical signal is defined as the average signal power to noise power $\mathrm{SNR}=[\mathrm{I} 2 / \sigma 2]$. The spectra of different users do not overlap because of the zero cross correlation property of MD code. The variations of the photodetector, as result of the detection of an ideally unpolarized thermal light that is generated by spontaneous emission can be expressed as follows:

$$
\sigma^{2}=I_{s h}^{2}+I_{t h}^{2}+I_{I M D}^{2}
$$

Let $C_{K}(i)$ denote the $\mathrm{i}^{\text {th }}$ element of the $\mathrm{K}^{\text {th }} \mathrm{MD}$ code sequences. According to the properties of MD code, direct detection technique can be written as follows:

$\sum_{i=1}^{N} C_{K}(i) C_{l}(i)= \begin{cases}W, & \text { For } \quad K=l \\ 0, & \text { Else. }\end{cases}$

The following assumptions are made [13,14]:

Each light source is ideal unpolarized and its spectrum is flat over the bandwidth [vo- $\left(\mathrm{v} / 2, \mathrm{vo}^{+}(\mathrm{v} / 2]\right.$, where vo is the central optical frequency and $\Delta \mathrm{v}$ is the optical source bandwidth expressed in Hertz.

1. Each power spectral component has an identical spectral width.

2. Each user has equal power at the receiver.

3. Each bit stream from each user is synchronized.

These assumptions are necessary for mathematical straight forwardness. Without these assumptions, the system would be difficult to analyze when the power for each spectral component is not identical and each user has a different power at the receiver.

It considers that the situation of optical propagation between points under water. Consider a laser transmitting a total power (PT) at the wavelength. The signal power received at the communications detector can be expressed as $[15,16,17]$.

$$
P_{s r}=P_{\text {trans }} \frac{D^{2}}{\vartheta_{\text {div }}{ }^{2} \times L^{2}} 10^{\frac{-\alpha_{\text {spec }} \times L}{10}} \tau_{\text {trans }} \times \tau_{\text {rec }}
$$

where $\mathrm{D}$ is the receiver diameter, $\vartheta$ is the divergence angle, $\alpha$ is the attenuation factor $(\mathrm{dB} / \mathrm{m}), \tau_{\text {trans }}, \tau_{\text {rec }}$ are the transmitter and receiver optical efficiency respectively. The power spectral density (PSD) of the received optical signals can be written as follows [18]:

$$
r(v)=\frac{P_{s r}}{\Delta v} \sum_{K=1}^{K} d_{K} \sum_{i=1}^{N} c_{K}(i) \operatorname{rect}(i)
$$

where $\mathrm{P}_{\mathrm{sr}}$ is the effective power of a broadband source at the 
receiver, $\mathrm{K}$ represents the active users, $\mathrm{N}$ is the MD code length, and $d_{k}$ is the modulation data of nth subcarrier channel on the $\mathrm{K}^{\text {th }}$ optical codeword, which can be expressed as follows [12]:

$d_{k}(t)=\sum_{n=1}^{N c} u_{n, K}(t) m_{n, K} \cos \left(w_{n} t\right)$

where ${ }^{u_{u}(t)}$ is the normalized digital signal at the $\mathrm{n}^{\text {th }}$ subcarrier channel of the $\mathrm{K}^{\text {th }}$ codeword, $w_{n}{ }^{t}$ is the angular subcarrier frequency, $m_{n, K}$ is the modulation index of the $\mathrm{n}^{\text {th }}$ subcarrier of the $\mathrm{K}^{\text {th }}$ user, and $N_{c}$ is the number of the subcarrier channel on each codeword $[12,18,19]$. An identical modulation index is assumed for all subcarrier channels as follows:

$0 \leq m_{n, K} \leq \frac{1}{N_{c}}$,

The $\operatorname{rect}(i)$ is error function in Eq. (8) is given by

$\operatorname{rect}(i)=u\left[v-v_{0}-\frac{\Delta v}{2 N}(-N+2 i-2)\right]-u\left[v-v_{0}-\frac{\Delta v}{2 N}(-N+2 i]=u\left[\frac{\Delta v}{N}\right]\right.$

where $u(v)$ is the unit step function expressed as follows:

$u(v)= \begin{cases}1, & v \geq 0 \\ 0, & v<0\end{cases}$

To compute the integral of ${ }^{G(v)}$, we first consider an example of PSD (denoted by ${ }^{G}(v)$ of the received superimposed signal), as shown in Fig. 2. Here, ${ }^{A(i)}$ is the amplitude of the signal of the $\mathrm{i}^{\text {th }}$ spectral slot with width of $\frac{\Delta v}{N}$.

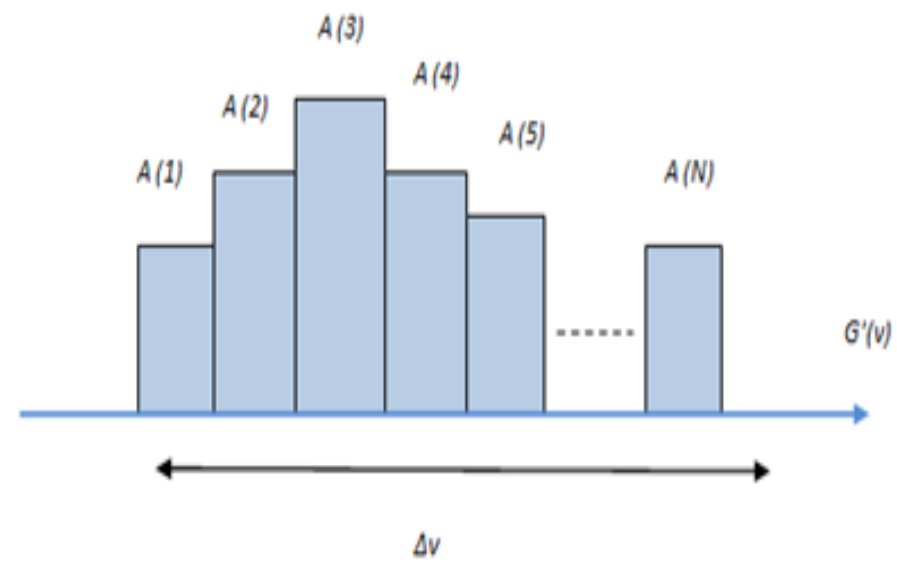

Figure 2: PSD of the Received Signal r(v).

The total power incident at the input of the Photodetector shown in Figure. 2 is given by:

$$
\begin{aligned}
& \int_{0}^{\infty} G(v) d v=\int_{0}^{\infty}\left[\frac{P_{s r}}{\Delta v} \sum_{K=1}^{K} d_{K}(t) \sum_{i=1}^{N} C_{K}(i) C_{l}(i) \operatorname{rect}(i)\right] d v \\
& \int_{0}^{\infty} G(v) d v=\int_{0}^{\infty}\left[\frac{P_{s r}}{\Delta v} \sum_{K=1}^{K} d_{K}(t) \sum_{i=1}^{N} C_{K}(i) C_{l}(i)\left[\frac{\Delta v}{N}\right]\right] d v
\end{aligned}
$$

$$
\begin{aligned}
& \int_{0}^{\infty} G(v) d v=\left[\frac{P_{s r}}{\Delta v}\right] \cdot\left[\frac{\Delta v}{N}\right] \sum_{K=1}^{K} d_{K}(t) \sum_{i=1}^{N} C_{K}(i) C_{l}(i) \\
& \int_{0}^{\infty} G(v) d v=\left[\frac{P_{s r}}{N}\right] \cdot \sum_{K=1}^{K} d_{K}(t) \sum_{i=1}^{N} C_{K}(i) C_{l}(i) \\
& \int_{0}^{\infty} G(v) d v=\left[\frac{P_{s r} W}{N}\right] \cdot \sum_{K=1}^{K} d_{K}(t)+\left[\frac{P_{s r}}{N}\right] \sum_{K=1, K \neq l}^{N} d_{K}(t) \\
& \int_{0}^{\infty} G(v) d v=\left[\frac{P_{s r} W}{N}\right] \cdot d_{l}
\end{aligned}
$$

The photocurrent can be expressed as follows:

$$
I=\mathfrak{R} \int_{0}^{\infty} G(v) d v
$$

where $\Re$ is the responsiveness of the photodetectors given by $\Re=\frac{\eta e}{h_{c}}$ [13].

Here, $\eta$ is the quantum efficiency, $\mathrm{h}$ is Planck's constant $(6.66 \times 10-34 \mathrm{Js})$, and $\mathrm{vc}$ is the central frequency of the original broadband optical pulse. Then, Eq. (13) can be expressed as follows:

$$
I=\mathfrak{R} \int_{0}^{\infty} G(v) d v=\frac{\mathfrak{R} P_{s r} W}{N} \sum_{n=1}^{N c} u_{n, K}(t) m_{n, K} \cos \left(w_{n} t\right)
$$

At the RF demodulator, the signal is coherently mixed with a local oscillator $2 \cos \left(w_{n} t\right)$ [11]. Therefore, Eq. (14) can be expressed as follows:

$$
\begin{gathered}
I=\frac{\mathfrak{R} P_{s r} W}{N} \sum_{n=1}^{N c} u_{n, K}(t) m_{n, K} \cos \left(w_{n} t\right)\left[2 \cos \left(w_{n} t\right)\right], \\
I=\frac{\Re P_{s r} W}{N} \sum_{n=1}^{N c} u_{n, K}(t) m_{n, K}\left[1+\cos \left(2 w_{n} t\right)\right],
\end{gathered}
$$

The frequency double component can be filtered out by using LPF; consequently, the modulator output becomes

$$
I=\frac{\mathfrak{R} P_{s r} W}{N} u_{n, K}(t) m_{n, K}
$$

The noise power of shot noise can be written as follows [18]:

$$
\begin{aligned}
I_{s h}^{2} & =2 e B \Re\left[\int_{0}^{\infty} G(v) d v\right], \\
& =2 e B \Re\left[\frac{\Delta v}{N}\right] \cdot\left[\frac{P_{s r} W}{\Delta v}\right], \\
& =\frac{2 e B \Re P_{s r} W}{N},
\end{aligned}
$$

The probability of sending bit " 1 " at any time for each user is 0.5 ; thus, Eq. (17) becomes 


$$
I_{s h}^{2}=\frac{e B \Re P_{s r} W}{N} .
$$

Thermal noise is given by [18]:

$$
I_{\text {th }}^{2}=\frac{4 K_{b} T_{n} B}{R_{L}} .
$$

where $K_{b}, T_{n}, B$, and $R_{L}$ represent Boltzmann constant, absolute receiver noise temperature, noise equivalent electrical bandwidth of the receiver, and receiver load resistor, respectively. Intermediation distortion is given by [20]:

$$
I_{I M D}^{2}=P_{s r}^{2} \Re^{2} m_{n, K}^{6}\left[\frac{D_{1,1,1}}{32}+\frac{D_{2,1}}{64}\right] .
$$

where $D_{1,1,1}$ is the three tone third order intermediation at $f_{i}+f_{K}-f_{l}$,

$D_{1,1,1}=\frac{N_{s}}{2}\left(N_{c}-N_{s}+1\right)+\frac{1}{4}\left\{\left(N_{c}-3\right)^{2}-5-\frac{1}{2}\left[1-(-1)^{N_{c}}\right](-1)^{N_{c}+N_{s}}\right\}$.

$D_{2,1}$ is the two-tone third order Intermodulation at $2 f_{i}-f_{K}$,

$$
D_{1,2}=\frac{1}{2}\left\{N_{c}-2-\frac{1}{2}\left[1-(-1)^{N_{c}}\right](-1)^{N_{s}}\right\} .
$$

Finally, using Eqs. (14), (16), (17), (18), and (19), we can compute the average SNR of the SCM-SAC-OCDMA-FSO system for the MD code as follows:

$$
S N R=\frac{\left[\frac{\Re P_{s r} W}{N} u_{n, K}(t) m_{n, K}\right]^{2}}{\frac{e B \Re P_{s r} W}{N}+\frac{4 K_{b} T_{n} B}{R_{L}}+P_{s r}^{2} \Re^{2} m_{n, K}^{6}\left[\frac{D_{111}}{32}+\frac{D_{21}}{64}\right]}
$$

with the use of Gaussian approximation, BER can be expressed as follows [7]:

$$
B E R=P_{e}=\frac{1}{2} \operatorname{erfc}\left(\sqrt{\frac{S N R}{8}}\right)
$$

\section{SYSTEM PARAMETERS OF SCM-SAC-OCDMA-FSO SYSTEM}

The proposed SCM-SAC-OCDMA-FSO system uses a light source to transfer data rate in the atmosphere. Therefore, the proposed system contributes to haze attenuation $\left(\alpha_{\text {spec }}\right)$ in SNR to calculate BER. SNR and BER are calculated by Eqs. (20) and (21) to evaluate the performance of the proposed system.

The system parameters shown in Table 1 are based on a previously published paper at $[1,21]$.
Table 1: Parameter Used in the Numerical Analysis.

\begin{tabular}{|l|l|l|}
\hline \multicolumn{1}{|c|}{ Symbol } & \multicolumn{1}{|c|}{ Parameter } & \multicolumn{1}{c|}{ Value } \\
\hline$\eta$ & $\begin{array}{l}\text { Photodetector } \\
\text { quantum efficiency }\end{array}$ & 0.6 \\
\hline $\mathrm{P}_{\text {sr }}$ & $\begin{array}{l}\text { Broadband effective } \\
\text { power }\end{array}$ & $5 \mathrm{dBm}$ \\
\hline $\mathrm{V}$ & Visibility & $23.3-50(\mathrm{~km})$ \\
\hline $\mathrm{Q}$ & Factor & $0.16 \mathrm{v}+0.43$ \\
\hline $\mathrm{B}$ & Electrical bandwidth & $500 \mathrm{MHz}$ \\
\hline$\lambda_{0}$ & $\begin{array}{l}\text { Operating } \\
\text { wavelength }\end{array}$ & $1550 \mathrm{~nm}$ \\
\hline $\mathrm{Rb}$ & Data bit rate & $1 \mathrm{~Gb} / \mathrm{s}$ \\
\hline $\mathrm{Tn}$ & $\begin{array}{l}\text { Receiver } \\
\text { temperature }\end{array}$ & $300 \mathrm{~K}$ \\
\hline $\mathrm{RL}$ & Receiver load resistor & $1030 \Omega$ \\
\hline $\mathrm{E}$ & Electron charge & $1.6 \times 10^{-19} \mathrm{C}$ \\
\hline $\mathrm{H}$ & Planck's constant & $6.66 \times 10^{-34} \mathrm{Js}$ \\
\hline $\mathrm{Kb}$ & $\begin{array}{l}\text { Boltzmann's } \\
\text { constant }\end{array}$ & $1.38 \times 10^{-23} \mathrm{~J} / \mathrm{K}$ \\
\hline $\mathrm{NC}$ & Number of carriers & $2-29$ \\
\hline $\mathrm{Ns}$ & $\begin{array}{l}\text { Number } \\
\text { subcarriers }\end{array}$ & $2-12$ \\
\hline $\mathrm{D}$ & $\begin{array}{l}\text { Receiver diameter } \\
\text { aperture }\end{array}$ & $32 \mathrm{~cm}$ \\
\hline$\tau_{\text {trans }}$ & $\begin{array}{l}\text { Transmitter optical } \\
\text { efficiency } \\
\text { respectively }\end{array}$ & $0.5 \%$ \\
& $\begin{array}{l}\text { Receiver optical } \\
\text { respectively }\end{array}$ & $0.5 \%$ \\
\hline$\tau_{\text {rec }}$ & Divergence angle & $1 \mathrm{~m} \mathrm{red}$ \\
\hline$\vartheta$ & & \\
\hline
\end{tabular}

\section{COMPARING BETWEEN SCM-SAC-OCDMA-FSO SYSTEM AND SAC-OCDMA-FSO SYSTEM BY USING MD CODE}

Figure 3 illustrates the BER performance, which was carried out against the number of active users for MD code in FSO communication under heavy haze. It can be observed that BER increases with the number of users. In addition, the results illustrate that the performance of the FSO system using SCM-SAC-OCDMA system with MD code is better than the FSO system using SAC-OCDMA system with MD code. Figure 4 shows the number of users that affects SNR, demonstrating that the SNR decreases during the heavy haze as a result of the increasing number of users.

Figure 4 also shows the SNR performance carried out against the transmission distance for different systems in FSO under heavy haze conditions. In addition, the results illustrate that the performance of the FSO using the proposed SCM-SAC-OCDMA system with MD code is better than the FSO using SAC-OCDMA system with MD code.

Figure 5 shows that the powerful force for the SAC-OCDMA system using FSO with MD code is higher than the proposed 
SCM-SAC-OCDMA-FSO system with MD code under haze conditions.

This proves that the SCM-SAC-OCDMA system using FSO with MD code performs sufficiently up to $5 \mathrm{dBm}$ and the system using the proposed SAC-OCDMA-FSO system with $\mathrm{MD}$ code performs only up to $6 \mathrm{dBm}$. Figure 6 show that the performance of the proposed SCM-SAC- OCDMA-FSO system affects the data rate. In addition, the figure shows the comparison between BER and data rate. The transmitted high data rate increases BER.

Therefore, if the data rate for the proposed SCM-SACOCDMA-FSO system is increased to $1 \mathrm{~Gb} / \mathrm{s}$, BER would reach $4.06 \times 10^{-14}$ during heavy haze comparing to SAC-OCDMA FSO system would reach $1.54 \times 10^{-8}$.

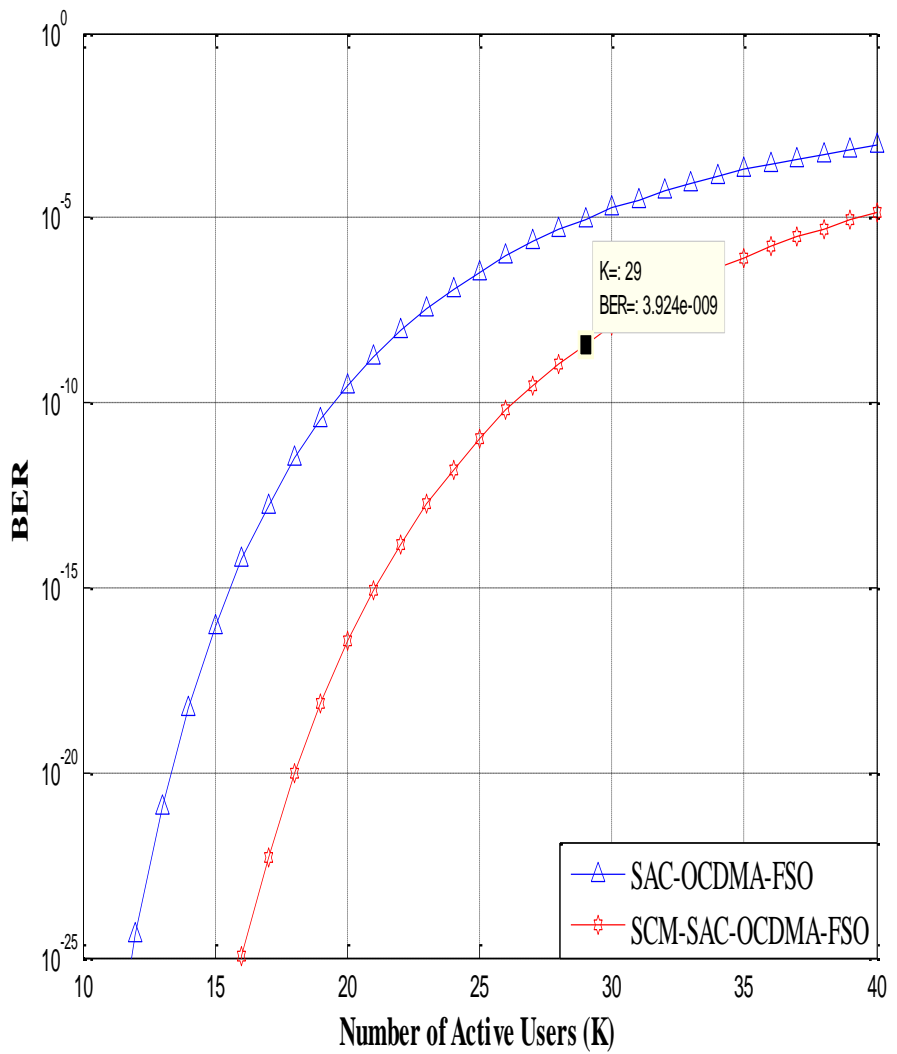

Figure 3: Number of Active Users against BER.

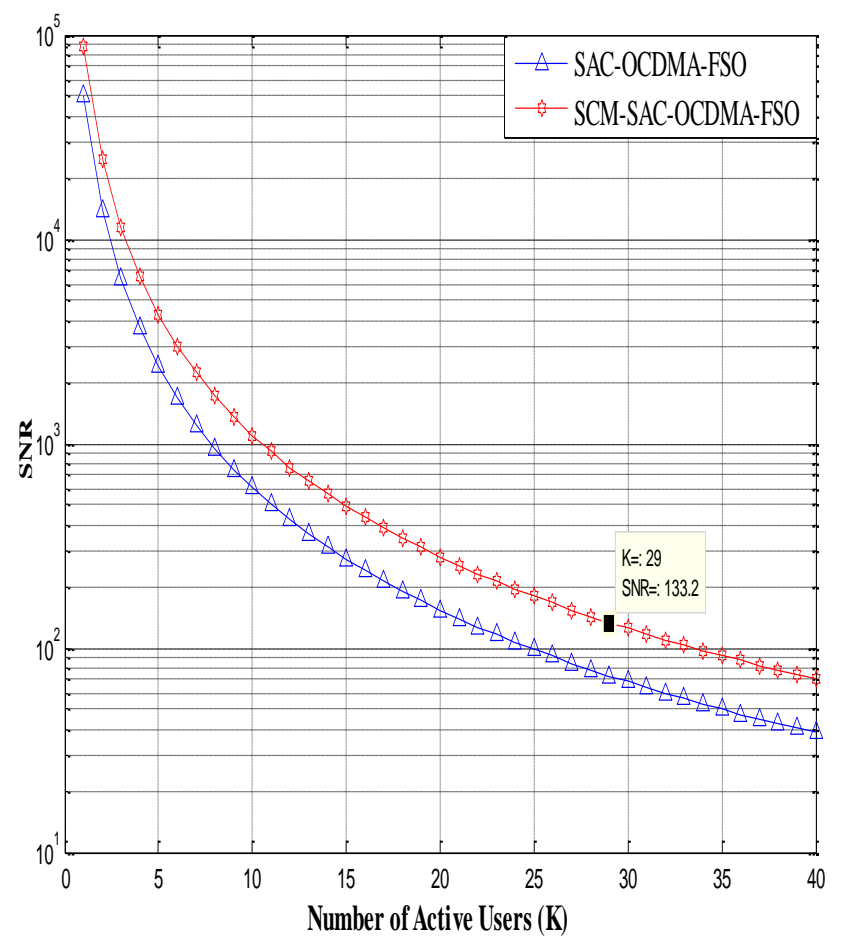

Figure 4: Number of Active Users versus SNR.

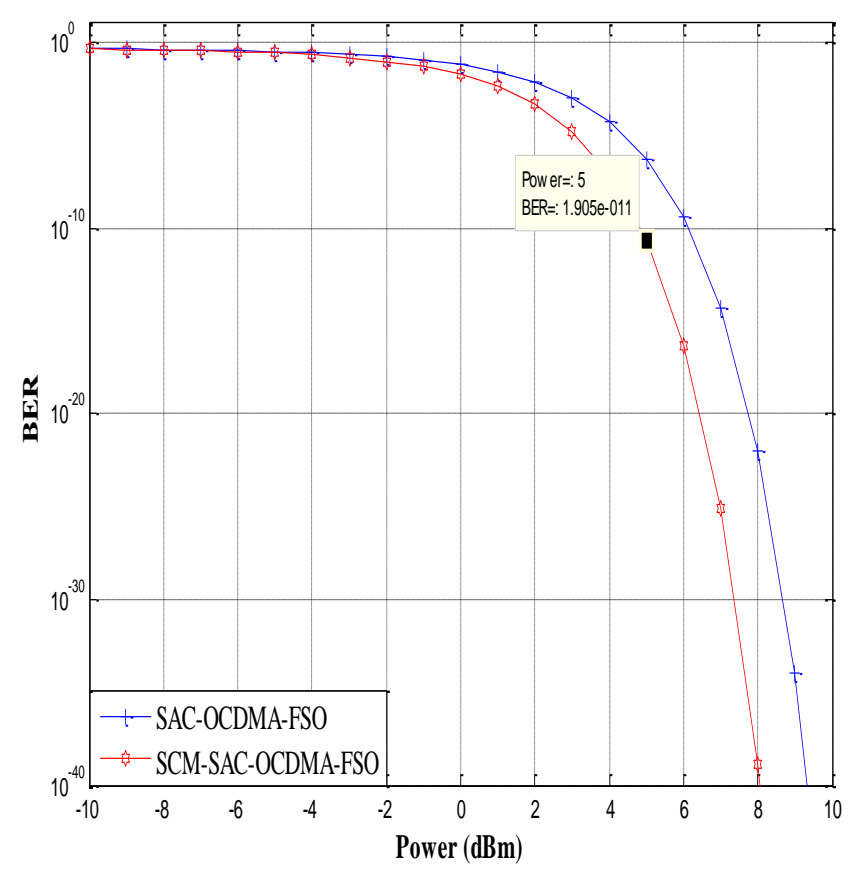

Figure 5: Power Force versus SNR. 


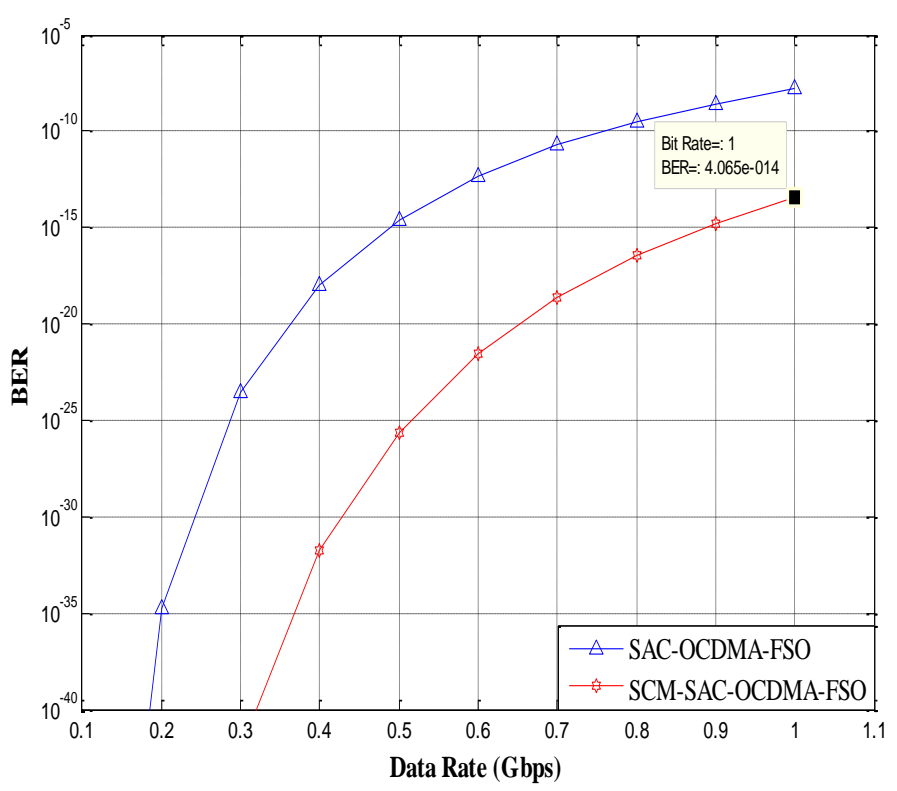

Figure 6: Data Rate versus BER.

\section{CONCLUSION}

FSO technology is a good alternative, especially when compared with fiber optics. This study discussed the advantages of using SCM-SAC-OCDMA system based on FSO using MD code. This system is proposed to evaluate the influences of different noise types, such as shot noise, thermal noise and intimidation distortion (IMD), as well as the effect of haze attenuation $\left[\alpha_{\text {spec }}\right]$ on received signal power $\left(\mathrm{P}_{\mathrm{sr}}\right)$. The proposed SCM-SAC-OCDMA-FSO system has been evaluated numerically, in a heavy haze condition, the proposed system can transmit $1 \mathrm{~Gb} / \mathrm{s}$ for $23.3 \mathrm{~km}$-with eight subcarriers under the transmission power of $5 \mathrm{dBm}$ at BER $6.4 \times 10^{-10}$. Additionally, the proposed system was compared with SAC-OCDMA system based on FSO by using MD code; it found that the performance of the proposed SCM-SACOCDMA-FSO system outweighs that of SAC-OCDMA system. Therefore, this paper has demonstrated through the analysis of various models and research that SCM-SAC -OCDMA can increase efficiency and capacity when data is transferred within a poor visibility environment such as Iraq, Australia and Malaysia.

\section{REFERENCES}

1. Abd T. H. Syed. A. A., Hilal A. F., Ibrahim F. R., Ahmad R. B., Performance improvement of hybrid SCM SAC-OCDMA networks using multilingual code Academic Journals, Vol. 7(11), pp. 1262-1272, 2012. https://doi.org/10.5897/SRE11.1664

2. Sahbudin, R., Syed A. A., Mohd A., Mohd bin A. S., Mohd M., Mahamod I., "Comparative performance of hybrid SCM SACOCDMA system using complementary and AND subtraction detection techniques International Arab Journal of Information Technology, 2008. 5(1): p. 61-65.

3. Sahbudin, R.K.Z., M.K. Abdullah, and M. Mokhtar, Performance improvement of hybrid subcarrier multiplexing optical spectrum code division multiplexing system using spectral direct decoding detection technique, Optical Fiber Technology, 2009. 15(3): p. 266-273.

4. Abd, T.H., Aljunid S. A., Fadhil H. A., Ahmad R. A., Design and simulation a new code with zero cross-correlation for SAC-OCDMA networks Australian Journal of Basic and Applied Sciences, 2012. 6(3): p. 112-119.

5. Sahbudin, R.K.Z., Mazlin K., Salasiah H., Makhfudzah M., Siti B. A. A., Performance of SAC OCDMA-FSO communication system, Optik, 2013. 124(17): p. 2868-2870.

6. Mohammed H.S., ALJUNID S. A., FADHIL H. A., ABD T. H., FAYADH R. A., RAHMAN A. K.., Generation of a new hybrid subcarrier multiplexing-SAC-OCDMA system based on FSO, Journal of Theoretical and Applied Information Technology, 2013. 58(2): p. 389-396.

https://doi.org/10.1109/ICOS.2013.6735074

7. Abda, F. H. T.H., Aljunid S.A., Fadhil H.A., Ahmad R.A., Modeling and simulation of multi diagonal code with zero cross correlation for SAC-OCDMA networks,IEEE explore, 2011.

8. Mustafa F. H., Simulation of FSO Transmission at Petaling Jaya due to Attenuations Effect, ELEKTRIKA, vol. VOL. 12, NO. 1, pp. 30-34, 2010.

9. Mustafa F. H., Effect of Rain Attenuations on Free Space Optic Transmission in Kuala Lumpur" International Conference on Advanced Science, Engineering and Information Technology, 2011.

10. Al Naboulsi M., et al., Fog attenuation prediction for optical and infrared waves, Optical Engineering, vol. 43, pp. 319-329, 2004.

11. Noshad M., M. Brandt-Pearce, Expurgated PPM using symmetric balanced incomplete block designs, IEEE Communications Letters, 2012. 16(7): p. 968-971.

12. Ahmed N. et al., Performance improvement of SAC-OCDMA system using modified double weight (MDW) code for optical access network, Academic Journal, vol. Vol. 7(7), pp. pp. 796- 804, 2012.

13. Smith E. D. J., Aljunid S.A., Fadil A., performance enhancement of spectral-amplitude-coding optical CDMA using pulse-position modulation, IEEE Transactions on Communications, 46(9), 1176-1185, 1998.

14. Wen, J.H., et al., Optical spectral amplitude coding CDMA systems using perfect difference codes and interference estimation, IEE Proceedings: Optoelectronics, 2006. 153(4): p. 152-160. https://doi.org/10.1049/ip-opt:20050015

15. Ajaybeer Kaur M.L.S., Performance Evaluation of Free Space Optics (FSO) and Radio Frequency Communication System Due to Combined Effect of Fog and Snow, International Conference on Recent Advances and uture Trends in Information Technology 
(iRAFIT2012).Proceedings published in International Journal of Computer Applications® (IJCA), 2012: p. 32-36.

16. Ali, M.A.A., Transmission of Optical Signals for Wireless Communications under SnowAttenuation Effect, American International Journal ofResearch in Science, Technology, Engineering \& Mathematics, 2013: p. $15-21$.

17. Rashed A.N.Z., El-Halawany M.M.E., Transmission characteristics evaluation under bad weather conditions in optical wireless links with different optical transmission windows, Wireless Personal Communications, 2013. 71(2): p. 1577-1595.

18. Chao-Chin Yang J.F. H., Shin-Pin T., Optical CDMA Network Codecs Structured With M-Sequence Codes OverWaveguide-Grating Routers, IEEE PHOTONICS TECHNOLOGY LETTERS, vol. 16, NO. 2, pp. 641-643, FEBRUARY 2004.

19. Fadhil H.A., Aljunid S.A., Ahmad R.B., Performance of random diagonal code for OCDMA systems using new spectral direct detection technique, Optical Fiber Technology, 2009. 15(3): p. 283-289.

20. Koshy B. J. et al., "Efficient modeling and evaluation of fiber-fed microcellular networks in a land mobile channel using a GMSK modem scheme" IEEE Journal on Selected Areas in Communications, 15(4), 694-706,1997.

21. Koshy B. J., Shankar P. M., Efficient modeling and evaluation of fiber-fed microcellular networks in a land mobile channel using a GMSK modem scheme, IEEE Journal on Selected Areas in Communications, vol. 15, pp. 694-706, 1997.

22. Sahbudin, R.K.Z., et al., Design and cost performance of decoding technique for hybrid subcarrier spectral amplitude coding-optical code division multiple access system, Journal of Computer Science, 2011. 7(10): p. 1525-1531.

https://doi.org/10.3844/jcssp.2011.1525.1531 